\title{
Assessing the spatial signature of European climate reconstructions
}

\author{
Ulf Büntgen ${ }^{1,2, *}$, Jörg Franke ${ }^{1}$, David Frank ${ }^{1}$, Rob Wilson ${ }^{3}$, Fidel González-Rouco ${ }^{4}$, \\ Jan Esper ${ }^{5}$ \\ ${ }^{1}$ Swiss Federal Research Institute WSL, 8903 Birmensdorf, Switzerland \\ ${ }^{2}$ Oeschger Centre for Climate Change Research (OCCR), University of Bern, 3012 Bern, Switzerland \\ ${ }^{3}$ University of St Andrews, St Andrews, Fife KY16 9AL, UK \\ ${ }^{4}$ University of Madrid, 28040 Madrid, Spain \\ ${ }^{5}$ Department of Geography, Gutenberg University, 55099 Mainz, Germany
}

\begin{abstract}
Much progress has recently been made in reconstructing European temperature variability over centuries to millennia. In contrast, there are only a few attempts at long-term precipitation and/or drought reconstruction, which are spatially less significant. Here we discuss the possibility of using climate reconstructions from tree-ring density and width to make spatially explicit estimates of European temperature and drought variability, respectively. Four experiments were performed to assess spatial field correlations of (1) parameter-specific mean reconstructions, (2) individual site reconstructions, (3) instrumental stations, and (4) model analogues. The simple mean of 4 temperature reconstructions from northern Scandinavia and high-elevation sites in the Tatra, Alps, and Pyrenees revealed a significant positive correlation $(\mathrm{r}>0.4)$ with the gridded Central European summer temperature south of $55^{\circ} \mathrm{N}$ and west of $25^{\circ} \mathrm{E}$. In contrast, the mean of 11 hydro-climatic reconstructions located between Sweden and Turkey had a significant positive correlation with only a handful of small patches scattered along an east-west corridor from the British Isles over Germany to the Baltic. The significant positive correlation increased to $71 \%$ of the European landmass between $35-70^{\circ} \mathrm{N}$ and $10^{\circ} \mathrm{W}-40^{\circ} \mathrm{E}$ when using the individual 4 temperature reconstructions instead. The 11 individual hydro-climatic reconstructions had a significant positve correlation with summer drought over only $16 \%$ of the area. The proxy-based correlation fields are greatly supported by the spatial significance of instrumental station measurements and model analogues corresponding to the initial tree-ring site locations.
\end{abstract}

KEY WORDS: Climate reconstruction · Dendroclimatology • Hydroclimatology • Tree rings • Temperature $\cdot$ Precipitation $\cdot$ Drought $\cdot$ Europe

\section{INTRODUCTION}

For the European/North Atlantic sector, much progress has recently been made in understanding climatic variations through studies of instrumental measurements, gridded indices, historical documents, tree-ring chronologies, phenological observations, multi-proxy compilations, and model simulations (see Jones et al. 2009 for a review). Long-term reconstructions of annually resolved temperature that use tree- ring maximum latewood density measurements are restricted to Northern Scandinavia (Grudd 2008), the Alps (Büntgen et al. 2006), Tatra (Büntgen et al. 2007), and Pyrenees (Büntgen et al. 2008). In contrast, ring width-based reconstructions of hydro-climatic fluctuations are mainly limited to lower latitudes (e.g. Akkemik \& Aras 2005), with exceptions in southern Scandinavia (Linderholm \& Molin 2005, Helama et al. 2009), and central-eastern Europe (Brázdil et al. 2002, Wilson et al. 2005, Büntgen et al. 2010). The ideal tree-ring 
proxy number and their locations necessary to capture spatially explicit patterns of European-scale climate variability are largely unknown. This picture becomes even more complicated when using traditional reconstruction methods that use a combination of individual records, and thus likely diminish their maximum spatial significance.

Here we assessed the ability of existing tree-ring density- and width-based climate reconstructions situated between northern Scandinavia and the Mediterranean to mimic European growing season temperature and drought variability. Our interest stems from a practical rather than a theoretical perspective, as we analyzed the temperature and precipitation co-variability of existing mean and individual climate reconstructions, complemented by the assessment of the spatial extension of temperature and precipitation relationships within instrumental measurements, as well as climate model simulations. A suite of experiments (Expts 1 to 4) was performed. The simple mean of 4 (11) available temperature (hydro-climatic) reconstructions was correlated against gridded European temperature (drought) indices (Expt 1); the 15 individual reconstructions were correlated against climate grids (Expt 2), while instrumental station measurements near to the proxy locations (Expt 3) and model analogues most similar to the temperature/precipitation reconstruction arrays (Expt 4) were both considered for verification of the spatial domains for which temperature and precipitation reconstructions provide useful information.

\section{EXPERIMENTS}

Expt 1. The simple mean of 4 density-based temperature reconstructions from thermal treeline sites was used for comparison to gridded temperature data, and the mean of 11 ring width-based hydro-climatic reconstructions from temperate forest sites was used for comparison to gridded drought metrics. Note that only final reconstructions are considered here, whereas simple chronologies were disregarded. Table 1 shows a summary of the selected data pool; note that minor differences between the originally published results on climate sensitivity and those reported here are most likely caused by deviations in the seasonal response windows, lagged climate variables, and calibration periods used. The mean temperature and drought reconstructions (using density and ring width, respectively) were correlated against gridded $\left(0.5 \times 0.5^{\circ}\right)$ growing season (A-S: April to September) temperature and the self-calibrated Palmer Drought Severity Index (scPDSI) over the 1901 to 1993 common period and the 35 to $70^{\circ} \mathrm{N}$ and $10^{\circ} \mathrm{W}$ to $40^{\circ} \mathrm{E}$ region (Climate
Research Unit TS3; Mitchell \& Jones 2005, van der Schrier et al. 2006). Spatial field correlation of the mean density record is $>0.4$ over Central Europe south of $55^{\circ} \mathrm{N}$ and west of $25^{\circ} \mathrm{E}$ (Fig. 1A). In contrast, spatial field correlation of the mean ring width record is $>0.4$ for only a few patches scattered along an east-west corridor from the British Isles, over Germany, to the Baltic (Fig. 1B).

Expt 2. The 4 temperature and 11 drought reconstructions (using density and ring width, respectively) were individually correlated against gridded A-S temperature and the scPDSI (1901 to 1993). Spatial field correlations of the density records against gridded A-S temperature are $>0.4$ for $71 \%$ of the European landmass (Fig. 1C). Correlations $>0.6$ are found over Northern Scandinavia $\left(>60^{\circ} \mathrm{N}\right)$ and Central Europe $\left(<50^{\circ} \mathrm{N}\right)$. Less variance is explained along a west-east corridor $\left(\sim 50\right.$ to $\left.55^{\circ} \mathrm{N}\right)$ from the British Isles to Eastern Europe $\left(>35^{\circ} \mathrm{E}\right)$ and from the Kola Peninsula to the Near East. In contrast, correlations $>0.4$ of the ring width records against gridded A-S scPDSI are limited to areas around the proxy sites, summing up to only $16 \%$ of the continent (Fig. 1D). This poor picture becomes even more pronounced when considering field correlations between 0.5 and 0.6. Correlations $>0.6$ are not reached in any region.

Expt 3. Spatial correlation fields based on instrumental measurements near the proxy locations (Table 1) confirm the proxy-based observations as obtained from Expt 2: 2 large fields of positive correlations with temperature are revealed over Central and Northern Europe, whereas much smaller clusters of generally lower correlations are revealed with precipitation (Fig. 1E,F). Spatial field correlations against gridded A-S temperature are $>0.6$ for most of Scandinavia and continental Europe, whereas correlations against precipitation are $>0.6$ for a limited region north of the Alpine arc. Non-significant correlations with precipitation dominate the high northern latitudes $\left(>60^{\circ} \mathrm{N}\right)$, the Mediterranean region $\left(<45^{\circ} \mathrm{N}\right)$, and most of Eastern Europe $\left(>20^{\circ}\right.$ E). Empirical Orthogonal Function (EOF) analysis additionally confirms these patterns: the first 4 EOFs explain $\sim 80 \%$ of European summer temperature variability, but the cumulative sum of the first 10 EOFs only explains $\sim 60$ and $55 \%$ of corresponding precipitation and scPDSI variability, respectively (not shown).

Expt 4. Reanalysis data (ERA-40; Uppala et al. 2005) of the grid-cells covering the proxy locations serve as targets for the analogue search among a suite of model simulations: a control and 2 forced ECHO-G runs (González-Rouco et al. 2006), the forced HadCM3 run (Tett et al. 2007), a COSMOS control run, and the COSMOS Millennium ensemble runs 1 and 2 (J. Jungclaus pers. comm.). Reanalysis data are restricted to a spatial resolution of $3.75 \times 3.75^{\circ}$ for the period 1958 to 


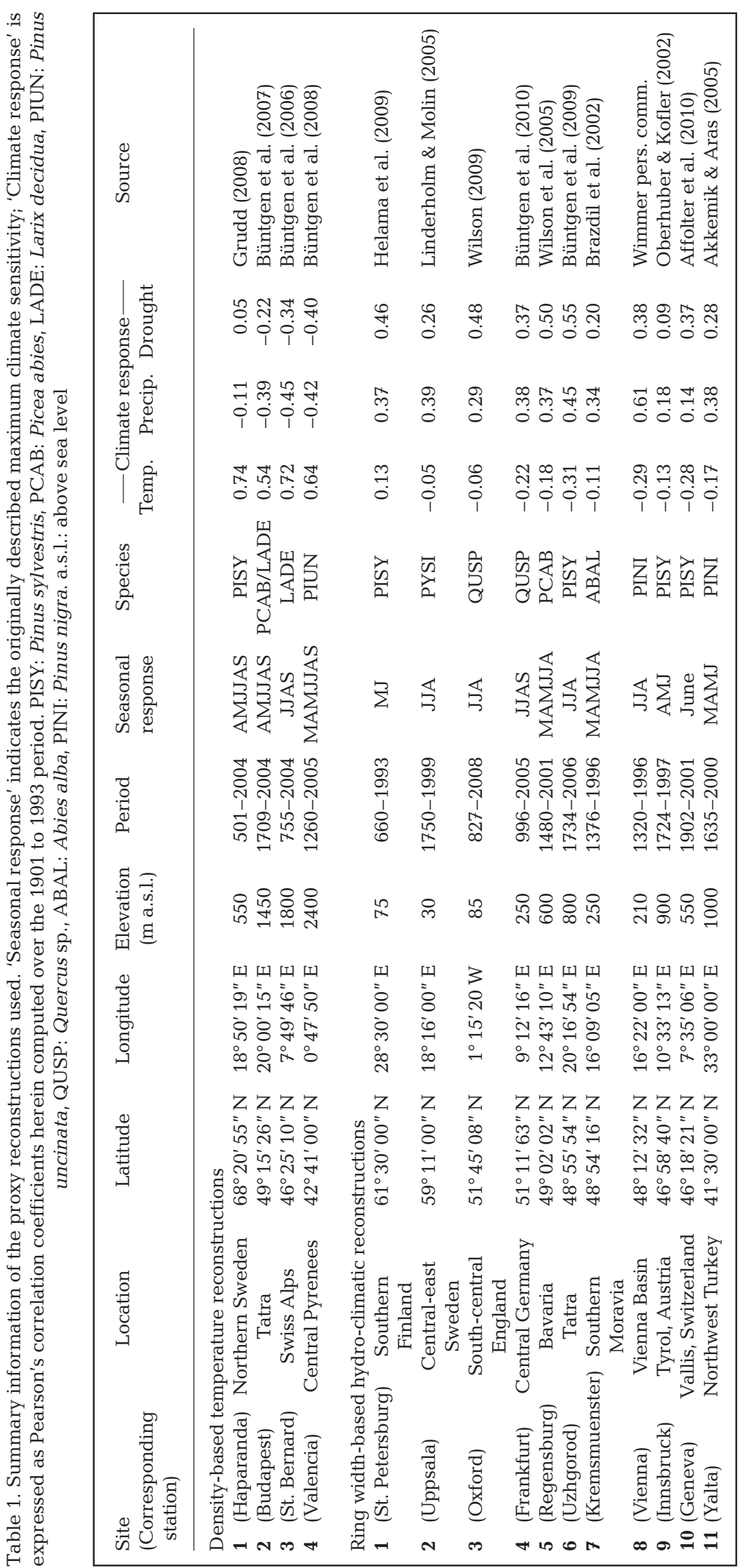

2002. The spatial field reconstructions of temperature and precipitation variability are obtained by the Proxy Surrogate Reconstruction method (PSR; Graham et al. 2007), which combines the advantages of climate models in simulating physically-consistent climate fields with the strength of proxy data (here time-series extracted from the ERA-40 dataset) that target the real climate trajectory (see also Goosse et al. 2006, Trouet et al. 2009). This combination is achieved by selecting the model states (analogues) that are most similar with proxy/instrumental data available at specific places and specific moments of time. Composites of the 10 closest model analogues for $\mathrm{A}-\mathrm{S}$ temperature and precipitation are used. Spatial fields of explained A-S temperature and precipitation variability, as derived from the shuffled model analogues of the PSR method, are in general agreement with the spatial correlation patterns of the proxy and instrumental records (Fig. 1G,H). The relatively coarse model resolution tends to amplify the area of explained variability, but does not change the main conclusion, i.e. precipitation is characterized by much higher local variability than temperature, and many more sites are required for reliable spatial precipitation reconstructions, whereas relatively robust spatial temperature estimates can be generated from only a couple of welllocated proxy records.

\section{CONCLUSIONS}

Independent methodological lines of tree-ring proxy, instrumental station, and model simulation evidence show a high degree of spatial temperature covariance in contrast to much more fragmented precipitation variability over the European/North Atlantic sector. Four temperature reconstructions based on density measurements from Scandinavia, the Alps, Tatra, and Pyrenees reveal correlations $>0.4$ with summer temperature over $71 \%$ of the European landmass. In contrast, 11 ring width-based hydro-climatic reconstruc- 


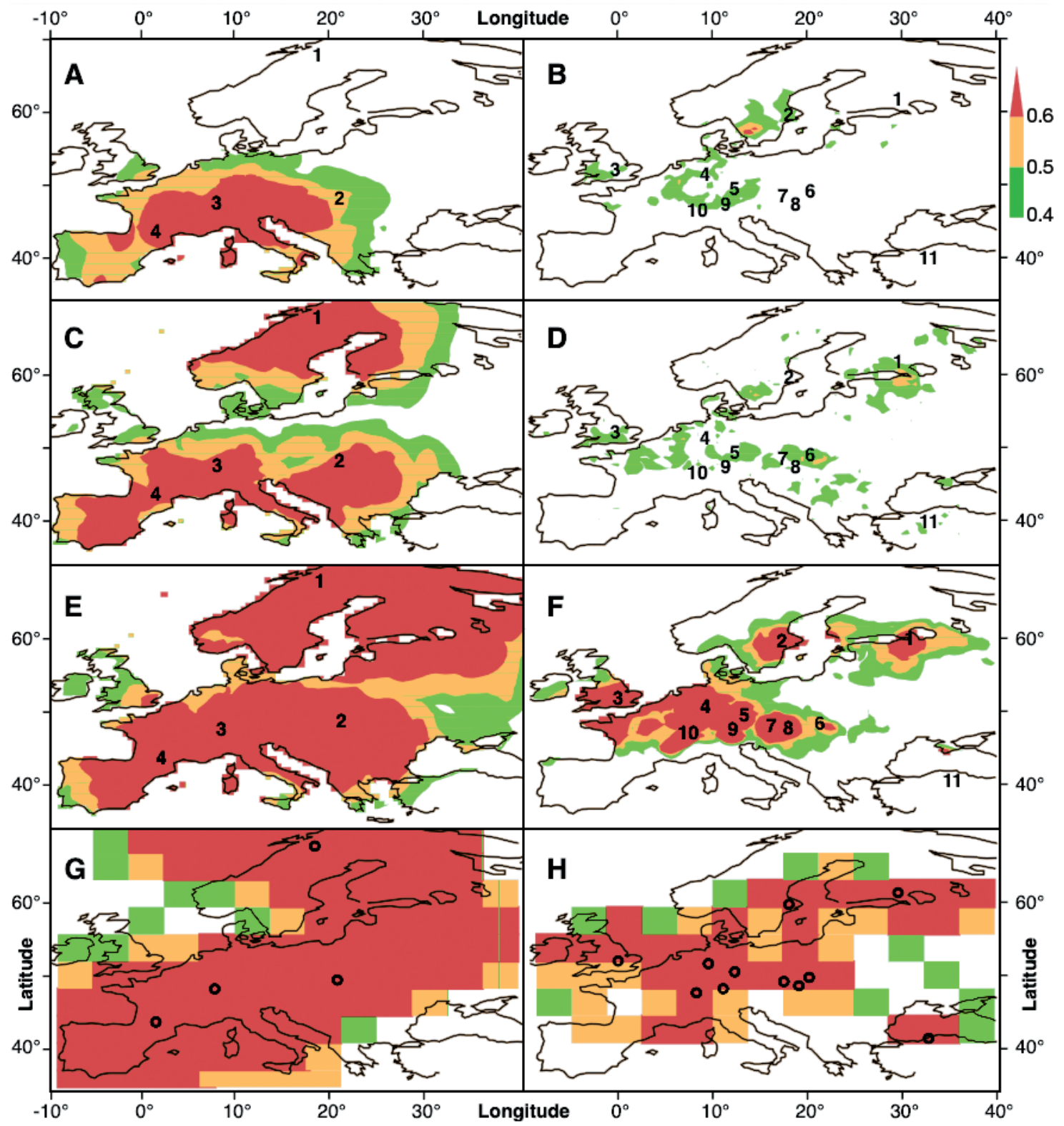

Fig. 1. Composite overlay maps of Pearson's correlation coefficients of the 4 experiments. Correlation fields computed from (A) the mean density and (B) ring width reconstruction (Expt 1), (C) the 4 individual density reconstructions, (D) the 11 ring width reconstructions (Expt 2), the instrumental (E) temperature and (F) precipitation measurements (Expt 3), and the model (G) temperature and $(\mathrm{H})$ precipitation analogues (Expt 4). Circles/numbers correspond to tree-ring sites listed in Table 1

tions only correlate $>0.4$ with summer drought over $16 \%$ of the European landmass. Even though our results have been partially highlighted by other authors at larger scales (Jones et al. 1997 and references therein), our experimental setting allows a new perspective to be drawn for the European region.

Besides the re-evaluation of the enormous pool of existing European tree-ring chronologies, we emphasize the importance of methodological refinements of the assessments of proxy climate sensitivity and trend preservation (Frank et al. 2008). Additional hugely im- portant untapped paleoclimatic resources are the historical oak chronologies available for many different European regions (see Haneca et al. 2009 for a review), of which some have already been successfully utilized for climate reconstructions (Wilson 2009, Büntgen et al. 2010). Additional insights on past precipitation/ drought variability might also be obtained from isotopic analyses (Treydte et al. 2007), with specific priority given to the Mediterranean region, where quality and quantity of hydro-climatic proxy and target data are still low (Xoplaki et al. 2004), but where future 
rates of temperature increase and precipitation decrease are expected to be most rapid (see Luterbacher et al. 2006 for a review). Moreover, there remains a west-east corridor between $\sim 50$ and $60^{\circ} \mathrm{N}$ for which new reconstructions should be developed. Besides the limitations in capturing hydro-climatic variability, further caution is advised, as proxy noise generally increases for data further back in time, and thus the effective number of annual predictors necessary to estimate historical variations is greater than those needed to estimate contemporary conditions. In this regard, much more data from different regions and archives are necessary to capture past climate variability across the European/North Atlantic sector (Pauling et al. 2006). Documentary archives can contain exceptional information on the spatial characteristics of historical climate extremes, which could be used to address this issue (Dobrovolný et al. 2010). We advocate that multi-proxy compilations and their cross-validation become routine when reconstructing climate.

Due to the importance of tree-ring-based proxies to understand annual to centennial-long variations of past hydro-climatology, we recommend an emphasis on new sites and parameters that are primarily sensitive to moisture availability, well replicated, and processed to include high- to low-frequency information. Nevertheless, precipitation reconstructions across mountain regions will continue to be particularly difficult. Given the spatial character of existing temperature proxies, additional density composites spanning several centuries to millennia should be developed for Scotland and the Carpathian arc where potential has already been indicated (Popa \& Kern 2009, Wilson 2009).

Acknowledgements. We thank the authors who published the original tree-ring data, and 4 anonymous reviewers who helped improve the manuscript. The Climate Research Unit (CRU), Royal Netherlands Meteorological Institute (KNMI), and European Centre for Medium-Range Weather Forecasts (ECMWF) kindly made their data available. This study was supported by the European Union project MILLENNIUM (no. 017008-GOCE) and the SNSF (NCCR-Climate).

\section{LITERATURE CITED}

Affolter P, Büntgen U, Esper J, Rigling A, Weber P, Luterbacher J, Frank D (2009) Inner Alpine conifer response to 20th century drought swings. Eur J For Res doi:10.1007/s 10342-009-0327-x

Akkemik Ü, Aras A (2005) Reconstruction (1689-1994 AD) of April-August precipitation in the southern part of central Turkey. Int J Climatol 25:537-548

Brázdil R, Štěpánková P, Kyncl T, Kyncl J (2002) Fir tree-ring reconstruction of March-July precipitation in southern Moravia (Czech Republic), 1376-1996. Clim Res 20: 223-239
Büntgen U, Frank DC, Nievergelt D, Esper J (2006) Summer temperature variations in the European Alps, AD 7552004. J Clim 19:5606-5623

Büntgen U, Frank DC, Kaczka RJ, Verstege A, Zwijacz-Kozica T, Esper J (2007) Growth/climate response of a multi-species tree-ring network in the Western Carpathian Tatra Mountains, Poland and Slovakia. Tree Physiol 27:689-702

Büntgen U, Frank DC, Grudd H, Esper J (2008) Long-term summer temperature variations in the Pyrenees. Clim Dyn 31:615-631

Büntgen U, Brázdil R, Frank D, Esper J (2009) Three centuries of Slovakian drought dynamics. Clim Dyn doi:10.1007/s 00382-009-0563-2

Büntgen U, Trouet V, Frank D, Leuschner HH, Friedrichs D, Luterbacher J, Esper J (2010) Tree-ring indicators of German summer drought over the last millenium. Quat Sci Rev doi:10.1016/j.quascirev.2010.01.003

Dobrovolný P, Moberg A, Brázdil R, Pfister C and others (2010) Monthly, seasonal and annual temperature reconstructions for Central Europe derived from documentary evidence and instrumental records since AD 1500. Clim Change doi:10.1007/s10584-009-9724-x

Frank D, Bouriaud O, Wilson R, Battipaglia G and others (2008) A challenge for spatially explicit reconstructions: the climate response of trees is a function of climate. TRACE 6:31-36

González-Rouco JF, Beltrami H, Zorita E, von Storch H (2006) Simulation and inversion of borehole temperature profiles in surrogate climates: spatial distribution and surface coupling. Geophys Res Lett 33:L01703. doi:10.1029/2005GL 024693

Goosse H, Renssen H, Timmermann A, Bradley RS, Mann ME (2006) Using paleoclimate proxy-data to select optimal realisations in an ensemble of simulations of the climate of the past millennium. Clim Dyn 27:165-184

Graham NE, Hughes MK, Ammann CA, Cobb KM and others (2007) Tropical Pacific: mid-latitude teleconnections in medieval times. Clim Change 83:241-285

> Grudd H (2008) Torneträsk tree-ring width and density AD 500-2004: a test of climatic sensitivity and a new 1500 year reconstruction of northern Fennoscandian summers. Clim Dyn 31:843-857

> Haneca K, Šufar K, Beeckman H (2009) Oaks, tree-rings and wooden cultural heritage: a review of the main characteristics and applications of oak dendrochronology in Europe. J Archaeol Sci 36:1-11

Helama S, Meriläinen J, Tuomenvirta H (2009) Multicentennial megadrought in northern Europe coincided with a global El Niño-Southern Oscillation drought pattern during the Medieval Climate Anomaly. Geology 37:175-178

Jones PD, Osborn TJ, Briffa KR (1997) Estimating sampling errors in large-scale temperature averages. J Clim 10: 2548-2568

> Jones PD, Briffa KR, Osborn TJ, Lough JM and others (2009) High-resolution palaeoclimatology of the last millennium: a review of current status and future prospects. Holocene 19:3-49

Linderholm HW, Molin T (2005) Early nineteenth century drought in east central Sweden inferred from dendrochronological and historical archives. Clim Res 29:63-72

Luterbacher J, Xoplaki E, Casty C, Wanner H and others (2006) Mediterranean climate variability over the last centuries: a review. In: Lionello P, Malanotte-Rizzoli P, Boscolo R (eds) The Mediterranean climate: an overview of the main characteristics and issues. Elsevier, Amsterdam, p 27-148

> Mitchell TD, Jones PD (2005) An improved method of constructing a database of monthly climate observations and 
associated high-resolution grids. Int J Climatol 25:693-712

Oberhuber W, Kofler W (2002) Dendroclimatological spring rainfall reconstruction for an inner Alpine dry valley. Theor Appl Climatol 71:97-106

Pauling A, Luterbacher J, Casty C, Wanner H (2006) Five hundred years of gridded high-resolution precipitation reconstructions over Europe and the connection to largescale curculation. Clim Dyn 26:387-405

Popa I, Kern Z (2009) Long-term summer temperature reconstruction inferred from tree-ring records from the Eastern Carpathians. Clim Dyn 32:1107-1117

Tett SFB, Betts R, Crowley TJ, Gregory J and others (2007) The impact of natural and anthropogenic forcings on climate and hydrology since 1550. Clim Dyn 28:3-34

Treydte K, Frank D, Esper J, Andreu L and others (2007) Signal strength and climate calibration of a European treering isotope network. Geophys Res Lett 34:L24302. doi:10. 1029/2007GL031106

Trouet V, Esper J, Graham NE, Baker A, Scourse JD, Frank DC

Editorial responsibility: Geir Ottersen,

Oslo, Norway
(2009) Persistent positive North Atlantic Oscillation mode dominated the Medieval Climate Anomaly. Science 324: 78-80

- Uppala SM, Kallberg PW, Simmons AJ, Andrae U and others (2005) The ERA-40 re-analysis. QJR Meteorol Soc 131: 2961-3012

> van der Schrier G, Briffa KR, Jones PD, Osborn TJ (2006) Summer moisture variability across Europe. J Clim 19: 2818-2834

Wilson RJS (2009) Bringing the 'climate' back to British treerings. TRACE 7:8-17

Wilson RJS, Luckman BH, Esper J (2005) A 500 year dendroclimatic reconstruction of spring-summer precipitation from the lower Bavarian Forest region, Germany. Int J Climatol 25:611-630

Xoplaki E, González-Rouco JF, Luterbacher J, Wanner H (2004) Wet season Mediterranean precipitation variability: influence of large-scale dynamics and trends. Clim Dyn 23:63-78

Submitted: September 21, 2009; Accepted: February 2, 2010 Proofs received from author(s): March 13, 2010 